\title{
Spreading the word: information for quality
}

\author{
Fiona Moss
}

"Where is the wisdom we have lost in knowledge? Where is knowledge we have lost in information?" T S ELIOT

Information is the raw material of quality improvement. Without reliable information any systematic attempt to improve the quality of care is not possible.

Modern health care exists within an environment of escalating developments in information technology. But the ability to produce large quantities of data at the touch of a button must not be confused with need for reliable and relevant information. Advancements in information technology could have a major impact on the delivery of and access to information within the healthcare service, but to date the potential of modern information systems has not been realised. Most hospitals have computer systems to support some functions and collect some data; many general practices have systems to support a range of facilities, including keeping records; and systems such as Medline are available in many libraries to provide access to published medical literature. But many other applications of information technology within health care are possible with current technology - for example, "smart" cards containing a lifetime of medical records, library systems accessible at the clinical workface, or the use of interactive videodisks to help patients to make informed choices about healthcare interventions.

Rationalising delays in incorporating the best that technology can offer into health care allows us to ignore some deepset attitudes. Barriers to developing the potential of new technology include, of course, limited resources and lack of effective strategies for training and implementing new information systems. But much more fundamental problems that pervade all aspects of health care, including quality improvement, and impede effective use of information technology are an unwillingness put effort into seeking and using reliable and relevant data and a widespread lack of respect for the quality of information. These are issues more likely to be magnified by new technology than to be solved by it.

All information about the NHS is welcome, particularly to consumers starved of information. Statistics of NHS activity that inform much public debate illustrate the paucity of information about the functions of the NHS. Discussion about performance remains confined to those aspects of health care that can be measured, whatever their relevance. Ministers tell us that we treat more patients, but even healthcare professionals do not know how many are treated appropriately or effectively. League tables of hospital performance in activities such as waiting times in outpatient clinics have been published but do not offer real choices to consumers. ${ }^{1}$ All hospitals know the number of people waiting for an operation for 18 months or more, but they do not have information about outcomes from the operations that have been performed. More space in newspaper columns was filled with the story of a little girl who had to wait for an operation for her ear than was generated by the important debate about whether that operation was the appropriate way to improve her hearing. ${ }^{2}$ Even locally, in hospital audit meetings, counting activity may seem an easier option than looking for the type of information that will guide quality improvement.

The non-availability of accessible and reliable information about important aspects of quality restricts the range of inquiry into healthcare quality. Seeking those elements known to affect quality of care and asking the right questions about care are important first steps towards getting the right information for quality assessment. If the debate about quality is to go beyond activity then the sources of information for quality assurance need to reflect the different dimensions of the quality of care (box).

Dimensions of quality (after Maxwell $^{3}$ )
Effectiveness
Appropriateness
Efficiency
Acceptability
Access
Equity

Many interactions beween healthcare professionals and consumers are to exchange information: consumers to inform the professionals about their problems, the professionals to use their knowledge to offer the consumers interpretation and inform them about possible treatment options. Finally, the consumers should be encouraged to inform the professionals about the outcome of treatment.

This paper examines the exchange of information at three points within health care: handling information about the effectiveness of care; recording information about patients in notes; and valuing consumers as sources of information.

Information about effectiveness of care Providing effective and appropriate health care is a central function of the health service. 
Healthcare professionals in provider units should be aware of the data on effectiveness of care for both clinical practice and audit. Also district health authorities, family health services authorities, and others responsible for purchasing care need to appraise the available evidence of the effectiveness of healthcare interventions to help guide purchasing strategies for local populations. Even when reliable and relevant information is available to support the use of clinical interventions, it is clear that sometimes that information is not known, not understood, or simply ignored. Some patients are denied effective interventions, effective interventions are sometimes used inappropriately, and some interventions used are simply ineffective.

Information about the effectiveness and some aspects of appropriateness of clinical interventions is derived from the results of clinical research. Randomised controlled trials are the form of evaluation most likely to provide valid information about effectiveness, but other types of study, including well designed controlled but non-randomised studies or well designed case-control or cohort studies, can provide useful information pertinent to assessing effectiveness and appropriateness of interventions.

Appraising the evidence to support the use of any intervention is often not straightforward. The existence of equivocal or conflicting published results about effectiveness of clinical interventions makes assessing the merits of different approaches to care a complex task, made more difficult by the publication of poor quality studies with design faults that render their results invalid. Moreover, the sheer volume of published medical research, said to be increasing by $6 \%$ each year," and of "grey" literature of unpublished reports and papers also contribute to the herculean task of assimilating the information on effectiveness.

LOOKING FORWARDS: COPING WITH SCIENTIFIC EVIDENCE

Failure to accept the need for a systematic approach to interpreting the findings of clinical research and to ensure their proper dissemination has undoubtedly contributed to unnecessary patient morbidity and mortality. Moreover, it has taken many years for some information about clearly beneficial interventions to become accessible to clinical practitioners and thus accepted practice; for example, evidence from the first meta-analysis showing an impressive reduction in mortality from acute myocardial infarction by thrombolytic therapy was published six years before most review articles recommended this treatment for routine or specific use. ${ }^{5}$

Methods do exist for systematically reviewing the available published work on a subject and defining options for clinical practice and future research. Systematic reviews are in themselves complex and represent a task requiring a scrupulously scientific method. Such reviews or meta-analyses represent an important influence on the quality of care. But achieving improvements necessitates three further steps beyond the review process: disseminating the results, applying the results in practice, and updating as new relevant data become available.

The best example of the product of a systematic approach to effectiveness is the book Effective Care in Pregnancy and Childbirth, which presents more than 400 overviews of clinical trials on perinatal care. ${ }^{6}$ Published in two volumes and available on disk, this work has contributed enormously to the understanding of the effectiveness of perinatal care. In addition to providing analyses, the book also acts as focus for collaboration in research. Now that this information is available in this form it must be the responsibility of local purchasers and providers to ensure that they have access to it and they use it to guide local policy.

The establishment of the Cochrane Centre in Oxford in $1992,{ }^{7}$ as part of the NHS research and development programme to facilitate systematic reviews of randomised trials represents an important step towards a rational and systematic approach to clinical research, its interpretation, and its dissemination. Work at the centre includes setting up a register of randomised trials through worldwide collaboration and setting standards for clinical trials. Setting up the centre is far sighted. It represents a commitment to the quality of clinical science and embraces the responsibility for scientific analysis of the results of clinical research and, importantly, the connection between clinical scientist and clinical practitioner. The work of this centre will be an important source for quality improvement programmes.

Another initiative aimed at helping health care professionals assimilate information on effectiveness is the publication of Effective Healthcare Bulletins - one of the functions of the NHS Centre for Reviews and Dissemination at the University of York. This series, commissioned by the public health division of the Department of Health, is based on the premise that scientific evidence of proved effectiveness and acceptability criteria should be central to decisions about purchasing and providing care. The key task of this project is "to clarify effectiveness and acceptability of the target interventions [of each selected subject] and to produce recommendations based on interpretation of current evidence according to agreed and explicit criteria. The aim is to provide purchasers and providers with current and scientifically defensible information." 8

The bulletins are produced through a systematic process which starts with identifying the key questions that need to be answered; review of literature, including the "grey" or "semigrey" literature; and assessment of validity of the information derived from available studies and assessment of the evidence with techniques including meta-analyses and assessment of acceptability and cost effectiveness. As more clinical research is completed such bulletins will need to be revised and updated. 


\section{Effective Healthcare Bulletins}

Population screening for osteoporosis to prevent fractures

Formal rehabilitation after stroke

Issues of quality in providing services for

subfertile couples

Surgical interventions for glue ear

Managing depression in primary care

Cholesterol screening and cholesterol lowering treatment

Brief interventions and alcohol use

Criteria for selection of subjects include high resource implications, presence of uncertainty or dispute about effectiveness, and the possibility of impact on health gain. So far, in two years, seven bulletins have been produced (box) with edited versions of these published in Quality in Health Care. The time taken to cover just these aspects of clinical practice illustrates the complexity of deriving a synthesis of available information on the effectiveness of clinical interventions.

Many clinical interventions have not been subjected to any form of trial or test and yet information about such interventions is needed by all - providers, purchasers, and consumers. Introducing a purchasing function into health care has introduced a new and important pressure for information about effectiveness. Cash limited purchasers want to purchase the most cost effective interventions for their populations and have a clear need to know what is best value. The Anglia and Oxford Regional Health Authority's research and development department publishes a newsheet (the Bandolier) as local "bullets of effectiveness for health care." This newsheet outlines information on effectiveness of a range of topics, from minimal access surgery to baths for elderly patients, and draws attention to areas where research is required." Positive and collaborative relationships between purchasers and providers, such as "partnership sourcing," should engender an environment which will encourage healthcare professionals to seek information about effectiveness and to collect good, reliable information about the care provided.

PRACIICE GLIDELINES

One strategy for encouraging good practice and improving quality of care is through the use of clinical guidelines. Practice guidelines have been defined as systematically developed statements to assist practitioner and patient decisions about appropriate health care for specific clinical circumstances," 11 and factors assessing the validity of guidelines described. ${ }^{\circ}$ The greatest barrier to the use of guidelines is doctors' reluctance - for various reasons. ${ }^{12}$ But evidence does exist to support the role of guidelines in improving the process of care. ${ }^{13}$

Guidelines are most likely to work if they are produced locally. But this raises concern about the quality of the information embodied in guidelines written without the necessary rigour to ensure that the recommendations are based on the best available evidence. It is crucial that the information is the best available otherwise guidelines will simply be endorsing substandard practice. An approach to developing scientifically valid guidelines has been set out by Grimshaw and Russell. ${ }^{1+}$

Guidelines iestricted to only those aspects of care that are based on firm scientific evidence would be very thin! Published guidelines are likely to include information from various sources and to contain evidenced based practice as well as that based on "received wisdom" - because in some instances that will be the best source of available information about choice of intervention. Guidelines must have local applicability, and local guidelines, as distinct from national guidelines, are likely to contain operational detail. For any practice guidelines all users - those using them to guide practice and those using them to help to assess the quality of care - need to be aware of the various levels of importance of different elements contained within guidelines. Those aspects of care that have clear evidenced based implications for patient outcome should be mandatory, and these are the aspects of care that should be the focus for quality assessment.

\section{Local information about patient care}

The introduction of clinical audit and the movement from medical audit in favour of a multiprofessional approach makes sense. After all, no single profession has a monopoly on quality improvement and for most patients health care is the combined attention of different health professionals.

The rationale of quality assurance, clinical audit, or any quality improvement initiative whatever its title - is that systematic analysis of the quality of care will provide those involved in care with information to allow them to reflect on their performance and, when necessary, to change practice or process to improve care. To be able to assure and assess quality and knowingly to improve practice locally, information is needed about patient care within the local unit.

\section{PATIENT'S' RECORISS}

Much of the groundwork of quality improvement initiatives entails obtaining local information and packaging it into assimilable units. Information about care is usually derived retrospectively from patients' notes. Much audit time - and money - has gone into audit of the quality of notes. Even well constructed attempts to improve the quality of note taking have resulted in little sustained improvement. ${ }^{15} 10$ The quality of medical notes, particularly in terms of completeness of recording, remains in general unsatisfactory. But medical notes are the main source of local information about the quality of medical care. No standards exist for medical notes, and medical students rarely (if ever) are given instruction in note taking. Writing in the medical notes is a task that doctors "pick up" during their first junior posts and is often relegated to the most junior member of the team. Medical notes often contain only a patchy description of process of care and 
infrequently any reference to assessment of outcome.

\section{LOOKING FORWARDS: IMPROVING NOTES BY} SHARING RECORDS?

One sign of a historical lack of cohesion between the different healthcare professions is the continuing use of separate medical, nursing, and therapy notes to record patient care. General statements about the quality of medical notes may not apply to the records of patient care made by other healthcare professions. Nursing notes, for which standards have been set, ${ }^{17}$ contain different sorts of information from medical notes - for example, care plans and details of inquiries from relatives - and are more likely to contain details about patients' reactions and feelings about their admission. Moreover, pharmacists, who make many observations about prescribing practice and have a particular role in determining the quality of drug therapy, do not record their observations in any of the various patient records. ${ }^{18}$

A case has been put for integrating the records of all healthcare professionals into a single "patient record." 19 Perhaps as a first step a mechanism other than cumbersome, ineffective audits needs to be found to improve the quality of medical notes. But perhaps the poverty of information in medical notes reflects a general negligence about information. Indifference to the quality of information is a serious matter and a product of outlook, not technology. Until records improve and become a more complete source of information about patients' condition and care, the quality, scope, and accuracy of quality improvement programmes will remain limited. Eventually the written record will be substituted by electronic systems, but using them to their potential will depend on the written record being improved. Electronic information systems have great capacity and will increase the quantity of information, but it is the human input that affects the quality of information. That is an issue that needs to be addressed now.

\section{Information from consumers}

Finally, consumers are the real source of much of the information needed for assessing the quality of care. Consumers have much to say about health care but are often not heard or their views ignored. Marianne Rigge describes some of the realities of lack of consumer involvement and the improvements that have resulted from allowing consumers to put their views about the care they receive (p S2) ${ }^{20}$ She writes of a group of patients whose outcome was not as good as they had expected:

"Owing to the way the system works, there was no way in which the consultants concerned would have known of the disappointments and concern of these patients. In all probability their records showed that their operation went well, the patient had been discharged, and the junior doctor found nothing untoward at the follow up appointment, and that is all the hospital was likely to know of the outcome."20
Patients need access to information to allow them to take part in decisions about their own health care and to make choices about clinical interventions. But if consumers are to contribute more to quality assurance then not only do they need more information their voices and their opinions about health care need to be heard and to be taken account of. Information systems within the health service need to include consumers' views, opinions, and concerns. This cannot be achieved simply by introducing new technology. We have simply failed to ask consumers about the care they receive and its effects on them, and this has become a matter of institutional habit.

Avedis Donabedian assigned three major roles in quality assurance to the consumers of healthcare: as contributors to quality assurance; as targets of quality assurance; and, finally, as reformers of health care. ${ }^{21} \mathrm{He}$ outlined the central and influential role that belongs to the consumers of care as arbiters and standard setters of quality. Perhaps if consumers had the opportunity to develop these roles they would impress upon healthcare professionals the urgency for better information.

\section{Conclusions}

In organisations as complex in structure and function as those in health care the sources of information needed to drive a good quality service are diverse and range from published results of clinical trials or meta-analyses of the effectiveness of complex medical interventions to locally gathered information about patient assessed outcomes and perceptions of fairness and acceptability. It is tempting to look upon the different types of information as forming a hierarchy. But this is to misunderstand what quality improvement is about. If we are to become wiser about the processes and outcomes of health care, to be able to link the two more usefully, and to improve the quality of care so that patients get a better deal, then we need to respect all information. Attention must be given to the quality of information, to asking the right questions, and to recording information completely and accurately if we want to look forward to realising the potential that information technology has to offer health care.

1 The patient's charter. Hospital and ambulance services comparative performance guide. 1993-4. London: Department of Health, 1994.

2 Black N. Jennifer's ear: airing the issucs. Quality in Health Care 1992;1:213-4.

3 Maxwell $R$. Quality assessment in healthcare. BMf 1984;288:1470-2

4 de Solla Price D. The development and structure of the biomedical literature. In: Warren KS, ed. Coping with the biomedical literature. New York: Pracger, 1981.

5 Antman EM, Lau J, Mosteller F, Chalmers T. A comparison of results of meta-analyses of randomised control trials and recommendations of clinical experts. Treatments for myocardial infarction. $7 A M A$ 1992; Treatments

6 Chalmers I, Enkin M, Keirse MJNC, eds. Effective care in pregnancy and childbirth. Oxford: Oxford University Press, 1989.

7 Chalmers I. Getting to grips with Archie Cochrane's agenda. $B M \mathcal{1}$ 1992;305:786-8.

8 Long AF, Sheldon TA. Enhancing effective and acceptable purchaser and provider decisions. Quality in Health Care 1992;1:74-6. 
9 Moore A, McQuay H, Gray JAM, eds. Bandolier: bullets of effectiveness for health care. Anglia and Oxford Regional Health Authority Research and Developmen Department, 1994

10 Donaldson L. Building quality into contracting and purchasing. Quality in Health Care 1994;3 suppl: $\mathrm{S} 37-40$

11 Institute of Medicine. Guidelines for clinical practice: from development to use. Washington, DC: National Academic Press, 1992.

12 Delamothe $T$. Wanted: guidelines that doctors will follow. BMF 1993;307:218.

13 Grimshaw JM, Russell IT. Effects of clinical guidelines on medical practice. A systematic review of rigorous evaluations. Lancet 1993;342:1317-22.

14 Grimshaw J, Russell I. Achieving health gain through clinical guidelines. I. Developing scientifically valid guidelines. Quality in Health Care 1993;2:243-8.
15 Gabbay J, McNicol MW, Spiby J, Davies S. What did audit achieve? Lessons from preliminary evaluation of a year's medical audit. BMF 1990;300:526-9.

16 Rai GS. Lessons from preliminary evaluation of a year's medical audit. BMF 1990;301:874-5.

17 United Kingdom Council for Nursing, Midwifery, and Health visiting. Standards for records and record kecping. London: LKCC, 1993.

18 Cotter S, McKee M, Barber N. Pharmacists and prescribing: an unrecorded influence. Quality in Health Care 1993;2:75-6.

19 Williams JG, Roberts R, Rigby MJ. Integrated patient records: another move towards quality. Quality in Health Care 1993;2:73 4.

20 Rigge $M$. Involving patients in clinical audit. Quality in Health Care 1994;3 suppl:S2-5.

21 Donabedian A. Quality assurance in health care: consumers' role. Quality in Health Care 1992;1:247-51. 